\title{
Correction to: Decision-making at the limit of viability: differing perceptions and opinions between neonatal physicians and nurses
}

\author{
Hans Ulrich Bucher ${ }^{1 *}$, Sabine D. Klein ${ }^{1}$, Manya J. Hendriks ${ }^{1,2}$, Ruth Baumann-Hölzle ${ }^{3}$, Thomas M. Berger ${ }^{4}$, \\ Jürg C. Streuli ${ }^{2}$, Jean-Claude Fauchère ${ }^{1}$ and on behalf of the Swiss Neonatal End-of-Life Study Group
}

\section{Correction to: BMC Pediatr (2018) \\ https://doi.org/10.1186/s12887-018-1204-x}

Please be advised that following publication of the original article [1], it was brought to the authors' attention that they did not have permission to reproduce the questionnaire in Additional File 1, and so Additional File 1 has since been removed from the article.

In addition, please note that the following (required) statement was previously missing from the Acknowledgements of the article:

"We used the questionnaires developed for the EURONIC Project on 'Parents' information and ethical decision making in neonatal intensive care units: staff attitudes and opinions' (EU Contract n. BMH1-CT93-1242) with permission. Requests for use of the questionnaires should be addressed to Marina Cuttini (marina.cuttini@opbg.net; marinacuttini@gmail.com)."

Furthermore, after publication of the original article [1], the corresponding author noticed that the given names and family names of the members included in the Swiss Neonatal End-of-Life Study Group had been erroneously reverted in the initial publication.

These errors have all been corrected in the original article.

\section{Author details}

'Department of Neonatology, University Hospital Zurich, Frauenklinikstrasse 10, 8091 Zürich, Switzerland. ${ }^{2}$ Institute of Biomedical Ethics and History of Medicine, University of Zurich, Zurich, Switzerland. ${ }^{3}$ Dialogue Ethics Foundation, Interdisciplinary Institute for Ethics in Health Care, Zurich,

The original article can be found online at https://doi.org/10.1186/s12887018-1204-x

* Correspondence: buh@usz.ch

'Department of Neonatology, University Hospital Zurich, Frauenklinikstrasse

10, 8091 Zürich, Switzerland

Full list of author information is available at the end of the article
Switzerland. ${ }^{4}$ Neonatal and Paediatric Intensive Care Unit, Children's Hospital of Lucerne, Lucerne, Switzerland.

Published online: 31 January 2020

Reference

1. Bucher HU, Klein SD, Hendriks MJ, Baumann-Hölzle R, Berger TM, Streuli JC, Fauchère J-C, on behalf of the Swiss Neonatal End-of-Life Study Group. Decision-making at the limit of viability: differing perceptions and opinions between neonatal physicians and nurses. BMC Pediatr. 2018;18:81. https:// doi.org/10.1186/s12887-018-1040-z.

(C) The Author(s). 2020 Open Access This article is distributed under the terms of the Creative Commons Attribution 4.0 International License (http://creativecommons.org/licenses/by/4.0/), which permits unrestricted use, distribution, and reproduction in any medium, provided you give appropriate credit to the original author(s) and the source, provide a link to the Creative Commons license, and indicate if changes were made. The Creative Commons Public Domain Dedication waiver (http://creativecommons.org/publicdomain/zero/1.0/) applies to the data made available in this article, unless otherwise stated. 